\title{
Ketamine-induced bladder dysfunction is associated with extracellular matrix accumulation and impairment of calcium signaling in a mouse model
}

\author{
CHENG-HUANG SHEN ${ }^{1,2^{*}}$, SHOU-TSUNG WANG ${ }^{3,4^{*}}$, SHOU-CHIEH WANG ${ }^{3,5}$, \\ SHU-MEI LIN ${ }^{3}$, LEI-CHEN LIN ${ }^{6}$, YUAN-CHANG DAI ${ }^{7}$ and YI-WEN LIU ${ }^{4}$
}

\begin{abstract}
${ }^{1}$ Department of Urology, Chiayi Christian Hospital, Chiayi 600; ${ }^{2}$ Department of Health and Nutrition Biotechnology, Asian University, Taichung 41354; Departments of ${ }^{3}$ Food Science, and ${ }^{4}$ Microbiology, Immunology and Biopharmaceuticals, National Chiayi University, Chiayi 600; ${ }^{5}$ Division of Nephrology, Department of Internal Medicine, Kuang Tien General Hospital, Taichung 437; ${ }^{6}$ Department of Forestry and Natural Resources, National Chiayi University;

${ }^{7}$ Department of Pathology, Chiayi Christian Hospital, Chiayi 600, Taiwan, R.O.C.
\end{abstract}

Received September 12, 2018; Accepted January 7, 2019

DOI: $10.3892 / \mathrm{mmr} .2019 .9907$

\begin{abstract}
Due to the rising abuse of ketamine usage in recent years, ketamine-induced urinary tract syndrome has received increasing attention. The present study aimed to investigate the molecular mechanism underlying ketamine-associated cystitis in a mouse model. Female C57BL/6 mice were randomly divided into two groups: One group was treated with ketamine (100 mg/kg/day of ketamine for 20 weeks), whereas, the control group was treated with saline solution. In each group, micturition frequency and urine volume were examined to assess urinary voiding functions. Mouse bladders were extracted and samples were examined for pathological and morphological alterations using hematoxylin and eosin staining, Masson's trichrome staining and scanning electron microscopy. A cDNA microarray was conducted to investigate the differentially expressed genes following treatment with ketamine. The results suggested that bladder hyperactivity increased in the mice treated with ketamine. Furthermore, treatment with ketamine resulted in a smooth apical epithelial surface, subepithelial vascular congestion and lymphoplasmacytic aggregation. Microarray analysis identified a number of genes involved in extracellular matrix accumulation, which is associated with connective tissue fibrosis progression, and in calcium signaling regulation, that was associated with urinary bladder smooth muscle contraction. Collectively, the present
\end{abstract}

Correspondence to: Professor Yi-Wen Liu, Department of Microbiology, Immunology and Biopharmaceuticals, National Chiayi University, 300 Syuefu Road, Chiayi 600, Taiwan, R.O.C. E-mail: ywlss@mail.ncyu.edu.tw

*Contributed equally

Key words: bladder hyperactivity, calcium signaling pathway, fibrosis, ketamine, ketamine-induced cystitis, urinary bladder smooth muscle results suggested that these differentially expressed genes may serve critical roles in ketamine-induced alterations of micturition patterns and urothelial pathogenesis. Furthermore, the present findings may provide a theoretical basis for the development of effective therapies to treat ketamine-induced urinary tract syndrome.

\section{Introduction}

Ketamine, a non-competitive N-methyl-D-aspartic acid receptor antagonist, was discovered in 1961 and used as a clinical anesthetic (1). Ketamine-induced urinary tract syndrome has received increasing attention due to the rising illicit use of ketamine as a recreational drug among young adults. Previous studies investigated the ketamine-induced urological sequelae $(2,3)$, and it was demonstrated that long-term ketamine abuse may cause lower urinary tract syndromes (LUTS) that resemble interstitial cystitis (4). LUTS are associated with decreased bladder capacity, incontinence, hematuria and suprapubic pain resulting from neurological disorders (4). A number of possible factors responsible for the association between ketamine and LUTS have been proposed on the basis of clinical observations (5), including direct toxic damage on the urothelium causing bladder barrier dysfunction, chronic neurogenic inflammation and immunoglobulin E-mediated hypersensitivity. However, the causative mechanism underlying the association between ketamine abuse and ketamine-associated cystitis $(\mathrm{KC})$ remains unclear.

An increasing number of studies investigating the causes of $\mathrm{KC}$ have used in vivo rodent models. Accumulating evidence demonstrated that certain specific molecular factors, including cyclooxygenase- 2 and inducible nitric oxide synthase $(6,7)$ may interact with the submucosa inflammatory environment caused by ketamine abuse in clinical cases. In addition, oxidative stress mediated by mitochondria- and endoplasmic reticulum-dependent pathways was identified to be involved in the apoptosis of bladder cells and urothelial defects (8). A previous study demonstrated that long-term treatment 
with ketamine may lead to submucosa fibrosis, which is associated with epithelial-mesenchymal transition (EMT) mediated by transforming growth factor- $\beta 1$ (TGF- $\beta 1$ ) (9). LUTS-associated voiding dysfunctions were identified to be associated with an increased protein expression level of P2X purinergic receptor 1 (P2RX1) (10), and the downregulation of phosphorylated (p-) transgelin (TAGLN) was identified to be associated with the detrusor overactivity occurring in $\mathrm{KC}$ (11).

Due to the unclear etiology and the unavailability of clinical treatments for $\mathrm{KC}$, a genomic approach, using microarray analyses to identify the molecular factors underlying $\mathrm{KC}$, represents an effective strategy for the development of adequate therapies. Our previous studies based on microarray analysis examined a Balb/c mouse model $(12,13)$. Administration of low-dosage and short-term ketamine $(30 \mathrm{mg} / \mathrm{kg} /$ day for 8 weeks) induced a significant decrease in keratin 14 expression in urothelial tissue, suggesting that ketamine was able to damage the urothelial cell structure (12). Furthermore, using high-dosage, long-term ketamine injections $(100 \mathrm{mg} / \mathrm{kg} /$ day for 20 weeks), the expression levels of numerous genes involved in the chronic wound healing response were altered, suggesting the presence of an initial stage of fibrosis from ketamine abuse (13). However, no obvious inflammatory and histological anomalies were identified in the bladders of control mice and mice treated with ketamine. The C57BL/6 mouse strain was demonstrated to exhibit increased Type 1 helper $\mathrm{T}$ cell-dominant responses compared with Balb/c mice, which presents the Type 2 helper T cell phenotype (14). Due to different inflammatory responses between these two strains, C57BL/6 mice were used in the present study to investigate the effect of ketamine on inflammation. The present study aimed to identify potential disease-associated genes that may help in characterizing the pathogenesis of $\mathrm{KC}$.

\section{Materials and methods}

Animals and drug treatment. A total of 40 6-week-old female C57BL/6 mice (weighing 16.9 $\pm 0.95 \mathrm{~g}$ ) were purchased from The National Laboratory Animal Center (Taipei, Taiwan). The animals were maintained in an animal care facility in The Biotechnology and Health Hall of National Chiayi University (Chiayi, Taiwan) for 1 week. A total of 20 7-week-old mice received a daily $100 \mathrm{mg} / \mathrm{kg}$ intraperitoneal injection of ketamine (Imalgene 1000; Merial; Boehringer Ingelheim International $\mathrm{GmbH}$, Ingelheim am Rhein, Germany) for 20 consecutive weeks to model the effects of ketamine abuse. A control group consisting of 20 mice was injected with saline solution. The mice were housed in polycarbonate cages, provided with food and water ad libitum, and maintained in a 12 -h light-dark cycle at $22 \pm 2^{\circ} \mathrm{C}$ with $60 \pm 5 \%$ humidity. The health conditions of the mice were monitored daily for 20 weeks by observing specific behaviors, including squeals, decreased locomotor activity and abnormal posture. The mice were weighed weekly. Each mouse was placed in a transparent polycarbonate cage and sacrificed by gradual-fill $\mathrm{CO}_{2}$ exposure with a displacement rate of $20 \%$ chamber volume $/ \mathrm{min}$. When impaired spontaneous breathing and unconsciousness were observed, the $\mathrm{CO}_{2}$ flow was maintained for $>1$ min. Cessation of cardiac activity was confirmed via palpation. All animal experiments were approved by The Institutional Animal Care and Use Committee of National Chiayi University (approval no. 104047) and according to the guidelines of The Animal Research: Reporting in vivo Experiments, recommended by The National Centre for the Replacement, Refinement and Reduction of Animals in Research (15).

Mouse voiding behavior analysis. At the end of the 20th week ( $n=16 /$ group; 4/group mice were excluded due a lack of voiding), urine-voiding characteristics were investigated using a modified voided stain on paper (VSOP) method (16). A total of $20 \mu \mathrm{l} / \mathrm{g}$ distilled water was supplied to each mouse. Following $30 \mathrm{~min}$, a mouse was placed in a standard polycarbonate mouse cage with filter paper (185 mm; Advantec Toyo Kaisha, Ltd., Tokyo, Japan) under the bottom grid. The voiding area and the number of urine spots $>0.5 \mathrm{~cm}$ in diameter were recorded for $2 \mathrm{~h}$. The urine stains on the filter papers were directly scanned into image files using a scanner, and the stained areas were calculated using Image J (version 1.47; National Institutes of Health, Bethesda, MD, USA) software.

Total RNA extraction. The mouse urinary bladders in each group (n=5/group) were incubated overnight in RNAlater Stabilization Solution (Sigma-Aldrich; Merck KGaA, Darmstadt, Germany) and subsequently homogenized in TRIzol $^{\circledR}$ reagent (Invitrogen; Thermo Fisher Scientific, Inc., Waltham, MA, USA), according to the manufacturer's protocol. RNA concentration and purity were measured using the NanoDrop 1,000 spectrophotometer (Thermo Fisher Scientific, Inc., Wilmington, DE, USA), and purity was checked using ratios of absorbance values at 260/280 and 260/230 nm. The quality of RNA was assessed using the Bioanalyzer 2,100 (Agilent Technologies, Inc., Santa Clara, CA, USA), and three high-quality samples from each group were analyzed using an oligonucleotide DNA microarray.

Scanning electron microscopy (SEM) and histological examination. A total of seven bladders from sacrificed mice from each group ( $\mathrm{n}=7 /$ group) were inflated in situ with Bouin's fixative, as described in a previous study (17). Following removal, the bladders were incubated in Bouin's fixative at room temperature for $2 \mathrm{~h}$. Each bladder was subsequently cut longitudinally into strips, rinsed with PBS, and processed by dehydration in an ascending series of ethanol solutions, followed by overnight immersion in $100 \%$ acetone at $4^{\circ} \mathrm{C}$. Subsequently, the samples were critical point dried using liquid $\mathrm{CO}_{2}$ (HCP-2 critical point dryer; Hitachi, Ltd., Tokyo, Japan). The dried samples were subsequently mounted on an aluminum stub, sputter-coated with gold, and imaged using a S-3500N scanning electron microscope (magnification, $\mathrm{x} 500$ or $\mathrm{x} 900$ ) (Hitachi, Ltd.). A portion of mouse bladders ( $n=8 /$ group) was fixed in $10 \%$ phosphate-buffered formalin for $24 \mathrm{~h}$ at room temperature and subsequently embedded in paraffin and cut into 3-4 $\mu \mathrm{m}$ sections for subsequent histopathological observation. Hematoxylin and eosin (HE), and Masson's trichrome stainings were performed at room temperature to examine the morphology of the tissues by light microscope (magnification, $\mathrm{x} 200$ or $\mathrm{x} 400$ ).

Analysis of mouse oligonucleotide DNA microarray. The Mouse Whole Genome OneArray ${ }^{\circledR}$ (version 2; Phalanx 
Biotech Group, Hsinchu, Taiwan) contained 27,307 DNA oligonucleotide probes. Each probe consisted of 60 nucleotides and was designed in the sense direction. Among these probes, 26,423 corresponded to the genes annotated in the RefSeq v51 (https://www.ncbi.nlm.nih.gov/assembly/GCF_000001635.20/) and Ensembl v65 (https://www.ncbi.nlm.nih. gov/assembly/GCF_000001635.18/) databases. A total of 884 control probes were additionally included. Fluorescent antisense RNA (aRNA) targets were prepared from $1 \mu \mathrm{g}$ total RNA samples using the OneArray ${ }^{\circledR}$ Amino Allyl aRNA Amplification kit (Phalanx Biotech Group) and Cy5 dye (GE Healthcare, Chicago, IL, USA). The amplification was performed as follows. Firstly, RNA samples were mixed with first strand cDNA synthesized (FSS) in a PCR tube, followed by incubating for $10 \mathrm{~min}$ at $70^{\circ} \mathrm{C}$ in a thermal cycler. FSS enzyme was added and incubated for a further $1 \mathrm{~h}$ at $42^{\circ} \mathrm{C}$. Next, Second Strand Master Mix was added to each sample and incubated in the following conditions: $16^{\circ} \mathrm{C}$ for $15 \mathrm{~min}$, $37^{\circ} \mathrm{C}$ for $45 \mathrm{~min}, 65^{\circ} \mathrm{C}$ for $15 \mathrm{~min}$ and $4^{\circ} \mathrm{C}$ for $5 \mathrm{~min}$. Finally, In Vitro Transcription Master Mix was added to each sample and incubated for a further $16 \mathrm{~h}$ at $37^{\circ} \mathrm{C}$. Fluorescent targets were hybridized to the Mouse Whole Genome OneArray ${ }^{\circledR}$ with a hybridization buffer (Phalanx Biotech Group) using a hybridization system (Phalanx Biotech Group). Following $16 \mathrm{~h}$ of hybridization at $50^{\circ} \mathrm{C}$, non-specific binding targets were washed away. The slides were scanned using a DNA microarray scanner (G2505C; Agilent Technologies, Inc.), and the $\mathrm{Cy} 5$ fluorescent intensity of each spot was analyzed using GenePix software (version 4.1; Molecular Devices, LLC, Sunnyvale, CA, USA). Each sample was analyzed using technical and biological duplicates, with a reproducibility $>0.975$ (https://www.excelfunctions.net/excel-correl-function.html).

The signal intensity data were analyzed using the Rosetta Resolver $^{\circledR}$ system (Rosetta Biosoftware, Seattle, WA, USA) for data preprocessing and 75 percentile centering normalization. The sample errors were additionally estimated using an error-weighted method. The fold change and the P-value for pairwise sample comparison were calculated for evaluation of differentially expressed genes (DEGs). The DEGs meeting the criteria of $\log _{2}$ lfold changel $\geq 0.5$ and $\mathrm{P}<0.05$ were considered for further analysis.

Reverse transcription-quantitative polymerase chain reaction (RT-qPCR) analysis. A total of $2 \mu \mathrm{g}$ total RNA was used for RT using the High-Capacity cDNA RT kit (Applied Biosystems; Thermo Fisher Scientific, Inc.). Each reaction included 20 ng cDNA, forward and reverse primers at a concentration of $500 \mathrm{nM}$ and 2x Fast SYBR Green PCR master mix (Applied Biosystems; Thermo Fisher Scientific, Inc.). A total of $10 \mu \mathrm{l}$ reaction volume was used for RT-qPCR analysis with the appropriate primers. Each sample was tested in triplicate. A Bio-Rad CFX Connect real-time PCR machine (Bio-Rad Laboratories, Inc., Hercules, CA, USA) and Bio-Rad CFX Manager software (version 3.0; Bio-Rad Laboratories, Inc.) were used for the experimental setup and data analysis. The thermocycling conditions were as follows: $95^{\circ} \mathrm{C}$ for $5 \mathrm{~min}$, followed by 39 cycles of $95^{\circ} \mathrm{C}$ for $15 \mathrm{sec}$ and $60^{\circ} \mathrm{C}$ for $30 \mathrm{sec}$, and finally $95^{\circ} \mathrm{C}$ for $10 \mathrm{sec}$. The relative quantification was performed using the $2^{-\Delta \Delta C q}$ method (18). The RT-qPCR data of target genes were normalized to the reference gene GAPDH.
The gene analyzed with RT-qPCR and the respective primers were the following: Fibronectin (FN1)-Forward (F), 5'-CCT CGGGAATGGAAAGGGAG-3' and FN1-Reverse (R), 5'-ACG TGCAGGAGCAAATGGC-3'; versican (VCAN)-F, 5'-AGG AAGAGCAGACTGGAGTTGG-3' and VCAN-R, 5'-GCT GAGACCCAGGACCATGT-3'; potassium calcium-activated channel subfamily M $\alpha 1$ (KCNMA1)-F, 5'-CCATCCCGTCCA CAGCAAAT-3' and KCNMA1-R, 5'-AGGCATTATCCGGCT CATCTG-3'; potassium calcium-activated channel subfamily M regulatory $\beta$ subunit 4 (KCNMB4)-F, 5'-CTTCACCTG TGGCACCGACT-3' and KCNMB4-R, 5'-AGGGCGGGATAT AGGAGCAC-3'; ryanodine receptor 1 (RYR1)-F, 5'-TCCGCA AGCAGTATGAGGACC-3' and RYR1-R, 5'-AGTTCAGGA TCATCTGTCCCCAG-3'; protein kinase C $\beta$ (PRKCB)-F, 5'-TGCCCACCGATAGAGGTACA-3' and PRKCB-R, 5'-TGA CCAGGAACATCAGCATCT-3'; GAPDH-F, 5'-AAGGTC GGTGTGAACGGATT-3' and GAPDH-R, 5'-GTGAGTGGA GTCATACTGGAACAT-3'.

Gene pathway analysis. To investigate the biological function of the genes differentially expressed between the control mice and the mice treated with ketamine, the Kyoto Encyclopedia of Genes and Genomes (KEGG) database and NABA database (19) were used to analyze the DEGs and identify the enriched pathways. The 3,000 most significant DEGs were analyzed. Gene set enrichment analysis (GSEA; Molecular Signatures Database v6.2; http://software.broadinstitute. org/gsea/msigdb/collections.jsp) was used to perform data enrichment analysis based on the Canonical Pathway database. The pathways meeting the criterion of $\mathrm{P}<0.0005$ were considered for further analysis. Pathview (v1.4.2; https://www. bioconductor.org/packages/release/bioc/html/pathview.html), KEGGREST (v1.4.1; https://www.bioconductor.org/packages/release/bioc/html/KEGGREST.html) and KEGGgraph (v1.22.1; https://www.bioconductor.org/packages/release/bioc/ html/KEGGgraph.html) R packages (v3.1.1; https://cran.rproject.org/bin/windows/base/old/3.1.1/NEWS.R-3.1.1.html) were used for pathway visualization.

Statistical analysis. SigmaPlot (version 12.5; Systat Software, Inc., San Jose, CA, USA) was used for the statistical analyses. Data are presented as the mean \pm standard deviation or as the mean \pm standard error. The RT-qPCR results were calculated from experiments repeated three times. Statistical differences were assessed using Student's t-test. $\mathrm{P}<0.05$ was considered to indicate a statistically significant difference.

\section{Results}

Alteration of body weight in mice. All mice $(\mathrm{n}=40)$ survived the 20 -week treatments. Abnormal behaviors and body weight loss were not identified. However, the rate of weight gain in mice treated with ketamine significantly decreased from the first week, compared with control mice, and this trend continued for the remaining 19 weeks (Fig. 1). The weight of mice belonging to the control group increased by an average of $6.41 \mathrm{~g}$, whereas, the weight of the mice treated with ketamine increased by an average of $3.05 \mathrm{~g}$. The phenotype was consistent with the weight loss observed in cases of ketamine abuse in humans (20) and in previous animal studies $(10,13)$, and 
may be caused by reduced food consumption due to the side effects of ketamine, including dizziness, loss of appetite or nausea (21).

Effect of treatment with ketamine on voiding behavior of mice. To evaluate the effect of ketamine on bladder voiding function, the voiding area and urine spot numbers were recorded for $2 \mathrm{~h}$ using a modified VSOP method at the end of the 20th week. The spot areas of mice treated with ketamine were significantly decreased compared with control mice, whereas the spot numbers representing voiding frequency were increased compared with the controls (Fig. 2), thus suggesting that altered voiding function was induced by long-term treatment with ketamine.

Bladder histological examination. The urinary bladders of mice treated with ketamine exhibited significant histopathological alterations compared with the control group. At the end of the 20th week, mice treated with ketamine exhibited a smooth apical epithelial surface and subepithelial vascular congestion. In contrast, the apical side of the epithelium in the control group exhibited a rough surface (Fig. 3A). In addition, the mice treated with ketamine exhibited protrusive and enlarged mucosal folds resembling fibrous expansion of connective tissue stroma (Fig. 3B and C). However, signs of lymphoplasmacytic aggregation were detected in two bladder samples (Fig. 3A), suggesting that treatment with ketamine was not sufficient to induce inflammation in the majority of C57BL/6 mice.

SEM examination of the mice bladder epithelium. The apical surface of the mouse urinary epithelium is covered in scallop-shaped membrane plaques consisting of uroplakins and other integral membrane proteins (22). The SEM results suggested that the urothelial plaques of the control mice were intact, exhibiting a rough surface (Fig. 4A). In contrast, the plaques on the bladders of mice treated with ketamine were thinner and smoother, and tight junctions were identified around hexagon-shaped umbrella cells (Fig. 4B). These morphological alterations were consistent with the results of the HE staining, suggesting a smooth apical epithelial surface in bladders from mice treated with ketamine. However, no additional abnormalities, including denuded or detached urothelium, were identified, suggesting that the urothelial barrier function was not severely impaired following treatment with ketamine.

DEGs and pathways identified via microarray analysis. To analyze the gene network underlying $\mathrm{KC}$ development, a Mouse Whole Genome OneArray ${ }^{\circledR}$ was performed to determine the genes regulated by treatment with ketamine. Mice treated with ketamine presented 284 upregulated and 527 downregulated genes compared with control mice. Subsequently, to obtain a comprehensive overview of the identified DEGs and investigate their biological functions, GSEA was performed to examine the involved pathways, based on the KEGG and NABA database. The nine most significant pathways were identified (Fig. 5), including 'matrisome (ECM glycoproteins, matrisome and matrisome associated)', 'calcium signaling pathway', 'small cell lung cancer', 'MAPK signaling', 'regulation of actin

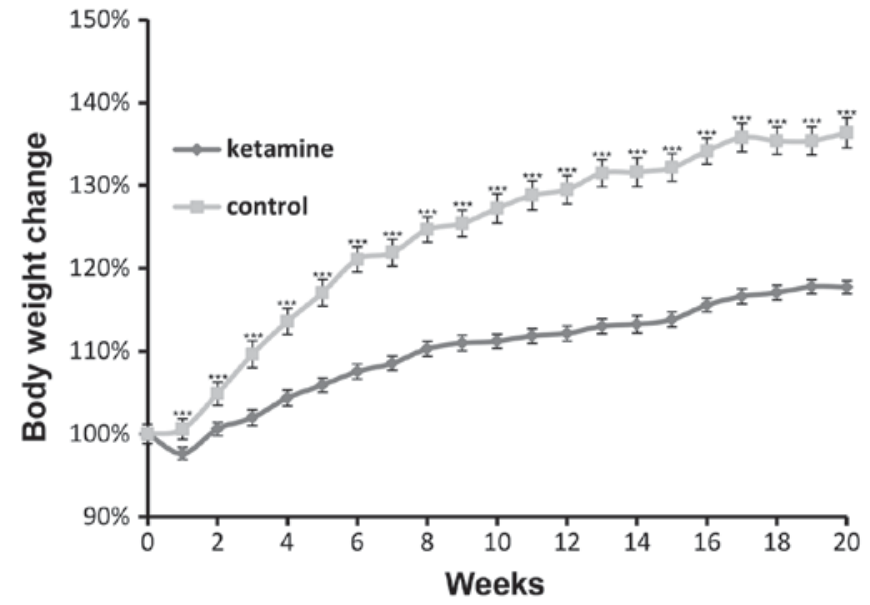

Figure 1. Alterations in mice body weight. Weight gain of mice treated with ketamine was significantly decreased compared with control mice. Data are presented as the mean \pm standard error. ${ }^{* * *} \mathrm{P}<0.001$ vs. respective control.

cytoskeleton', 'neuroactive ligand receptor interaction' and 'complement and coagulation cascades'. The DEGs involved in these pathways are presented in Table I. Extracellular matrix (ECM)- and calcium signaling-associated genes were considered for further analysis due to the role they serve in fibrosis and dysregulated micturition $(23,24)$.

Molecular components associated with ECM and calcium signaling are regulated by treatment with ketamine. Genes with a role in ECM, including FN1, fibulin 2, fibrinogen-like 2, laminin $\gamma 2$ (LAMC2) and collagen type $1 \alpha 2$ (COL1A2) were significantly upregulated (Table I), which was consistent with the histopathological stain results, as the bladders presented connective tissue expansion in the submucosa region (Fig. 3C). Additional ECM-associated genes VCAN, angiotensinogen (AGT) and C-type lectin domain family 4 member D were upregulated, suggesting a role for these genes in modulating the interactions between the ECM and neighboring cells, promoting a profibrotic milieu. Furthermore, genes with a role in the calcium signaling pathway were differentially expressed. In particular, genes associated with calcium transport and intracellular calcium storage were identified, including calcium/calmodulin-dependent protein kinase $2 \alpha$ (CAMK2A), RYR1, PRKCB, endothelin receptor type B (EDNRB) and phospholamban. Notably, calcium signaling may influence urinary bladder smooth muscle (UBSM) contraction (23). In addition, the large-conductance voltageand $\mathrm{Ca}^{2+}$-activated (BK) channel is the principal $\mathrm{K}^{+}$channel regulating local $\mathrm{Ca}^{2+}$ release by the RYRs, located in the sarcoplasmic reticulum membrane (25). Therefore, BK channels are able to regulate the frequency of $\mathrm{Ca}^{2+}$ sparks and subsequent UBSM excitability (25). Notably, two genes, KCNMA1 and KCNMB4, that constitute the $\alpha$ and $\beta$ subunits of the BK channels (23), were downregulated in mice treated with ketamine. To understand the role of these genes in the calcium signaling pathway, Pathview software was used to visualize the DEGs involved in this pathway (Fig. 6).

Furthermore, the expressions of six genes associated with calcium regulation were validated by RT-qPCR (Fig. 7). The RT-qPCR results suggested that KCNMB4 was significantly 
Table I. List of differentially expressed genes and significantly enriched pathways following treatment with ketamine.

A, Matrisome (systematic name: M5889)

\begin{tabular}{|c|c|c|c|c|}
\hline Gene symbol & $\begin{array}{c}\text { NCBI } \\
\text { gene ID }\end{array}$ & Gene name & Fold change & P-value \\
\hline CILP & 214425 & Cartilage intermediate layer protein & 1.12 & $3.44 \times 10^{-2}$ \\
\hline CLEC4D & 17474 & $\begin{array}{l}\text { C-type lectin domain family } \\
4 \text { member D }\end{array}$ & 1.08 & $1.44 \times 10^{-2}$ \\
\hline LAMC2 & 16782 & Laminin $\gamma 2$ & 0.95 & $2.24 \times 10^{-2}$ \\
\hline VCAN & 13003 & Versican & 0.88 & $1.30 \times 10^{-3}$ \\
\hline AGT & 11606 & Angiotensinogen & 0.82 & $4.10 \times 10^{-3}$ \\
\hline FN1 & 14268 & Fibronectin 1 & 0.79 & $8.25 \times 10^{-5}$ \\
\hline FGL2 & 14190 & Fibrinogen-like 2 & 0.64 & $1.17 \times 10^{-3}$ \\
\hline COL1A2 & 12843 & Collagen type $1 \alpha 2$ & 0.61 & $4.46 \times 10^{-2}$ \\
\hline FBLN2 & 14115 & Fibulin 2 & 0.60 & $2.46 \times 10^{-5}$ \\
\hline S100A2 & 628324 & $\begin{array}{l}\text { S100 calcium binding } \\
\text { protein } \mathrm{A} 2\end{array}$ & 0.59 & $3.51 \times 10^{-2}$ \\
\hline
\end{tabular}

B, Calcium signaling pathway (systematic name: M2890)

\begin{tabular}{|c|c|c|c|c|}
\hline Gene symbol & $\begin{array}{c}\text { NCBI } \\
\text { gene ID }\end{array}$ & Gene name & Fold change & P-value \\
\hline CHRNA7 & 11441 & Cholinergic receptor nicotinic $\alpha$ polypeptide 7 & -1.24 & $5.74 \times 10^{-5}$ \\
\hline CAMK2A & 12322 & $\begin{array}{l}\text { Calcium/calmodulin-dependent protein kinase } \\
2 \alpha\end{array}$ & -1.07 & $4.34 \times 10^{-3}$ \\
\hline RYR1 & 20190 & Ryanodine receptor 1 & -0.90 & $9.62 \times 10^{-7}$ \\
\hline CACNA1B & 12287 & $\begin{array}{l}\text { Calcium channel voltage-dependent } \mathrm{N} \text { type } \alpha 1 \\
\text { B subunit }\end{array}$ & -0.77 & $5.64 \times 10^{-3}$ \\
\hline BDKRB2 & 12062 & Bradykinin receptor, $\beta 2$ & -0.62 & $3.49 \times 10^{-3}$ \\
\hline NOS2 & 18126 & Nitric oxide synthase 2 & -0.61 & $1.17 \times 10^{-3}$ \\
\hline KCNMB4 & 58802 & $\begin{array}{l}\text { Potassium calcium-activated channel subfamily } \\
\text { M regulatory } \beta \text { subunit } 4\end{array}$ & -0.46 & $9.25 \times 10^{-2}$ \\
\hline KCNMA1 & 16531 & $\begin{array}{l}\text { Potassium calcium-activated channel subfamily } \\
\text { M } \alpha 1\end{array}$ & -0.35 & $1.29 \times 10^{-3}$ \\
\hline EDNRB & 13618 & Endothelin receptor type B & 0.53 & $9.31 \times 10^{-3}$ \\
\hline PLN & 18821 & Phospholamban & 0.53 & $2.91 \times 10^{-2}$ \\
\hline PRKCD & 18753 & Protein kinase $\mathrm{C} \delta$ & 0.53 & $2.84 \times 10^{-2}$ \\
\hline PRKCB & 18751 & Protein kinase $\mathrm{C} \beta$ & 0.46 & $2.45 \times 10^{-2}$ \\
\hline EDN1 & 13614 & Endothelin 1 & 0.40 & $2.50 \times 10^{-2}$ \\
\hline
\end{tabular}

C, Small cell lung cancer (systematic name: M3228)

\begin{tabular}{llll}
\hline Gene symbol & $\begin{array}{c}\text { NCBI } \\
\text { gene ID }\end{array}$ & \multicolumn{1}{c}{ Gene name } & Fold change \\
\hline E2F1 & 13555 & E2F transcription factor 1 & -0.69 \\
NFKB1 & 18033 & Nuclear factor of $\kappa$ light polypeptide gene & -0.63 \\
NOS2 & 18126 & enhancer in B cells 1 & -0.61 \\
LAMC2 & 16782 & Nitric oxide synthase 2 & 0.95 \\
FN1 & 14268 & Laminin $\gamma 2$ & 0.79 \\
\hline
\end{tabular}


Table I. Continued.

D, MAPK signaling (systematic name: M10792)

\begin{tabular}{lllll}
\hline Gene symbol & $\begin{array}{c}\text { NCBI } \\
\text { gene ID }\end{array}$ & \multicolumn{1}{c}{ Gene name } & Fold change & P-value \\
\hline DUSP8 & 18218 & Dual specificity phosphatase 8 & -1.26 & $1.60 \times 10^{-4}$ \\
HSPA1B & 15511 & Heat shock 70 kDa protein 1B & -0.79 & $3.52 \times 10^{-11}$ \\
CACNA1B & 12287 & Calcium channel voltage-dependent N type $\alpha 1$ B subunit & -0.77 & $5.64 \times 10^{-3}$ \\
NR4A1 & 15370 & Nuclear receptor subfamily 4 group A member 1 & -0.70 & -0.68 \\
RRAS2 & 66922 & Related ras viral oncogene homolog 2 & -0.65 & $3.04 \times 10^{-5}$ \\
FGF14 & 14169 & Fibroblast growth factor 14 & -0.63 & $3.66 \times 10^{-2}$ \\
DUSP1 & 19252 & Dual specificity phosphatase 1 & -0.63 & $3.99 \times 10^{-5}$ \\
NFKB1 & 18033 & Nuclear factor of $\kappa$ light polypeptide gene & $1.23 \times 10^{-5}$ \\
& & enhancer in B-cells 1 &
\end{tabular}

E, Regulation of actin cytoskeleton (systematic name: M18306)

\begin{tabular}{|c|c|c|c|c|}
\hline Gene symbol & $\begin{array}{c}\text { NCBI } \\
\text { gene ID }\end{array}$ & Gene name & Fold change & P-value \\
\hline INSRR & 23920 & Insulin receptor-related receptor & -0.90 & $7.72 \times 10^{-4}$ \\
\hline $\mathrm{F} 2$ & 14061 & Coagulation factor 2 & -0.74 & $4.86 \times 10^{-4}$ \\
\hline RRAS2 & 66922 & Related ras viral oncogene homolog 2 & -0.68 & $1.20 \times 10^{-9}$ \\
\hline FGF14 & 14169 & Fibroblast growth factor 14 & -0.65 & $3.66 \times 10^{-2}$ \\
\hline BDKRB2 & 12062 & Bradykinin receptor $\mathrm{B} 2$ & -0.62 & $3.49 \times 10^{-3}$ \\
\hline FN1 & 14268 & Fibronectin 1 & 0.79 & $8.25 \times 10^{-5}$ \\
\hline CFL2 & 12632 & Cofilin 2 & 0.68 & $2.07 \times 10^{-4}$ \\
\hline
\end{tabular}

F, Neuroactive ligand receptor interaction (systematic name: M13380)

\begin{tabular}{|c|c|c|c|c|}
\hline Gene symbol & $\begin{array}{c}\text { NCBI } \\
\text { gene ID }\end{array}$ & Gene name & Fold change & P-value \\
\hline OPRD1 & 18386 & Opioid receptor $\delta 1$ & -1.25 & $7.31 \times 10^{-6}$ \\
\hline CHRNA7 & 11441 & Cholinergic receptor nicotinic $\alpha 7$ & -1.24 & $5.74 \times 10^{-5}$ \\
\hline GHRHR & 14602 & Growth hormone releasing hormone receptor & -1.19 & $2.09 \times 10^{-3}$ \\
\hline $\mathrm{F} 2$ & 14061 & Coagulation factor 2 & -0.74 & $4.86 \times 10^{-4}$ \\
\hline GRIA2 & 14800 & Glutamate receptor ionotropic ampa 2 & -0.78 & $2.92 \times 10^{-2}$ \\
\hline BDKRB2 & 12062 & Bradykinin receptor $\mathrm{B} 2$ & -0.62 & $3.49 \times 10^{-3}$ \\
\hline PPYR1 & 19065 & Pancreatic polypeptide receptor 1 & 0.69 & $2.43 \times 10^{-3}$ \\
\hline
\end{tabular}

G, Complement and coagulation cascades (systematic name: M16894)

\begin{tabular}{|c|c|c|c|c|}
\hline Gene symbol & $\begin{array}{c}\text { NCBI } \\
\text { gene ID }\end{array}$ & Gene name & Fold change & P-value \\
\hline $\mathrm{F} 2$ & 14061 & Coagulation factor 2 & -0.74 & $4.86 \times 10^{-4}$ \\
\hline MASP1 & 17174 & Mannan-binding lectin serine peptidase 1 & -0.68 & $3.67 \times 10^{-2}$ \\
\hline C6 & 12274 & Complement component 6 & -0.67 & $1.82 \times 10^{-2}$ \\
\hline BDKRB2 & 12062 & Bradykinin receptor $\mathrm{B} 2$ & -0.62 & $3.49 \times 10^{-3}$ \\
\hline
\end{tabular}

Fold change values are expressed in $\log _{2}$ scale. NCBI, National Center for Biotechnology Information. 

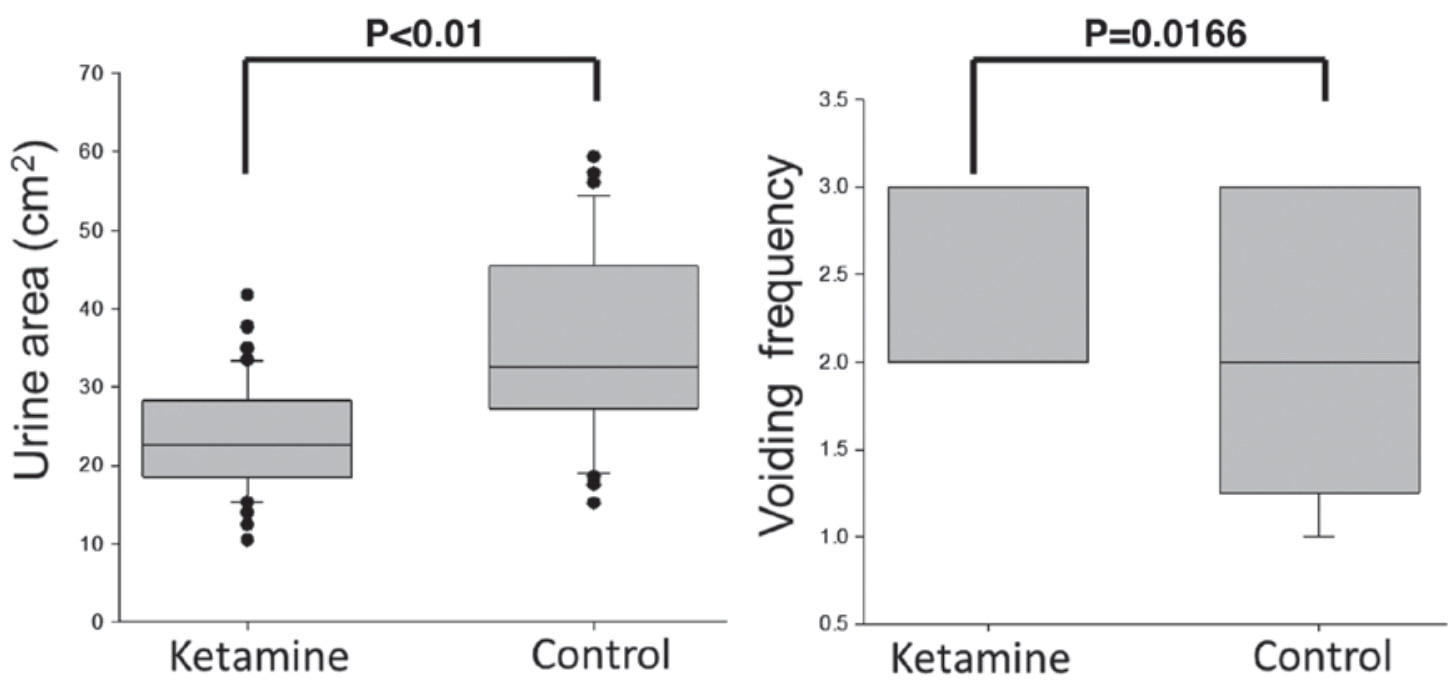

Figure 2. Voiding amount and frequency. Data were recorded using the modified voided stain on paper method at the end of the 20th week.
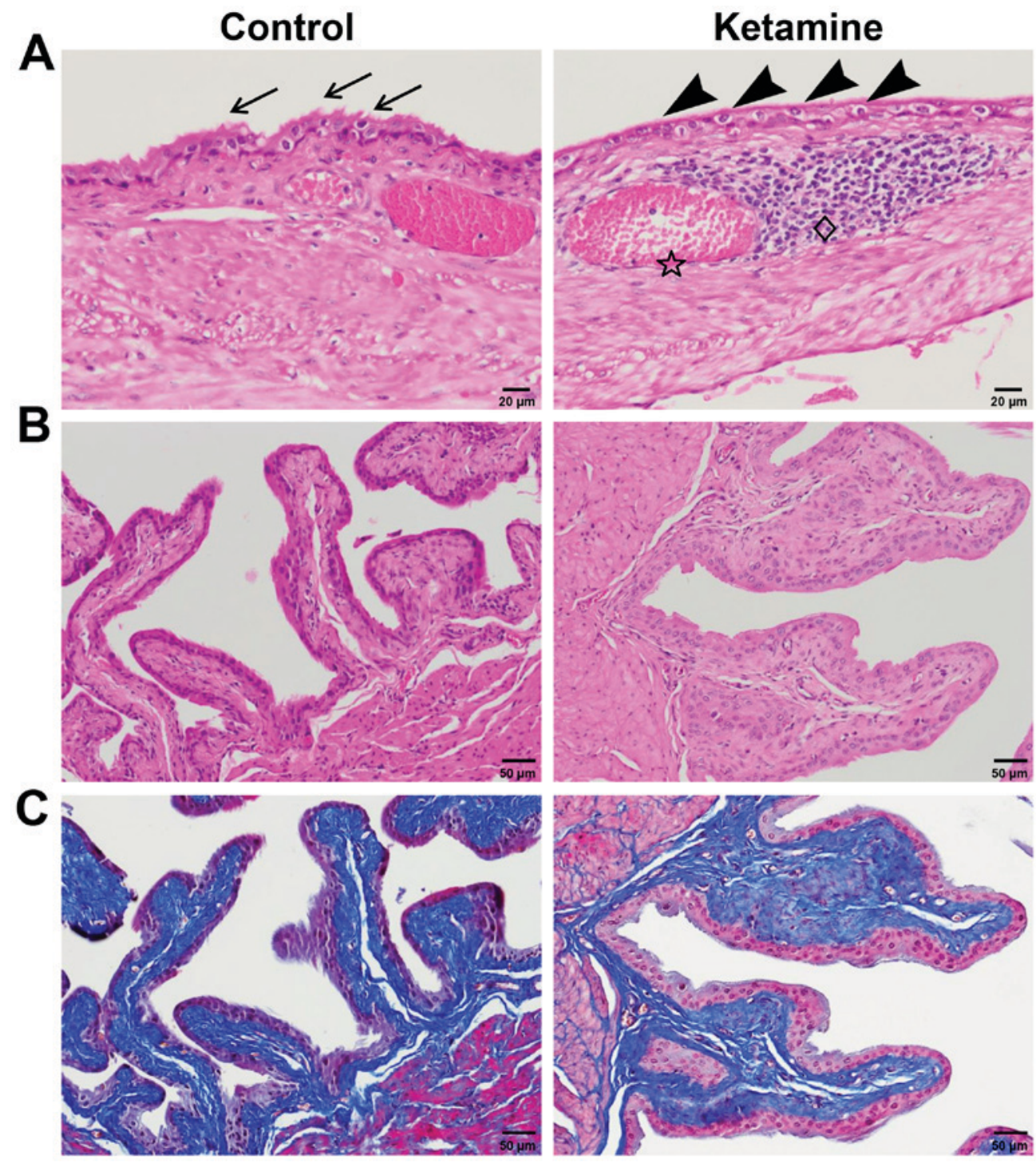

Figure 3. Histological examination of mice bladder tissues. (A) HE staining images of mice bladders in fully inflated status (magnification, x400). Black arrows indicate the rough apical epithelial surface in the control bladders, whereas, the black arrowheads indicate the smooth apical epithelial surface in bladders of mice treated with ketamine. The black star indicates the subepithelial vascular congestion and the black diamond indicates lymphoplasmacytic aggregation detected in mice treated with ketamine. (B) HE staining and (C) Masson's Trichrome staining images of mice bladders (magnification, x200). Control bladders exhibited thin mucosal folds, whereas, the mice treated with ketamine presented protrusive and enlarged mucosal folds in the connective tissue stroma. HE, hematoxylin and eosin. 

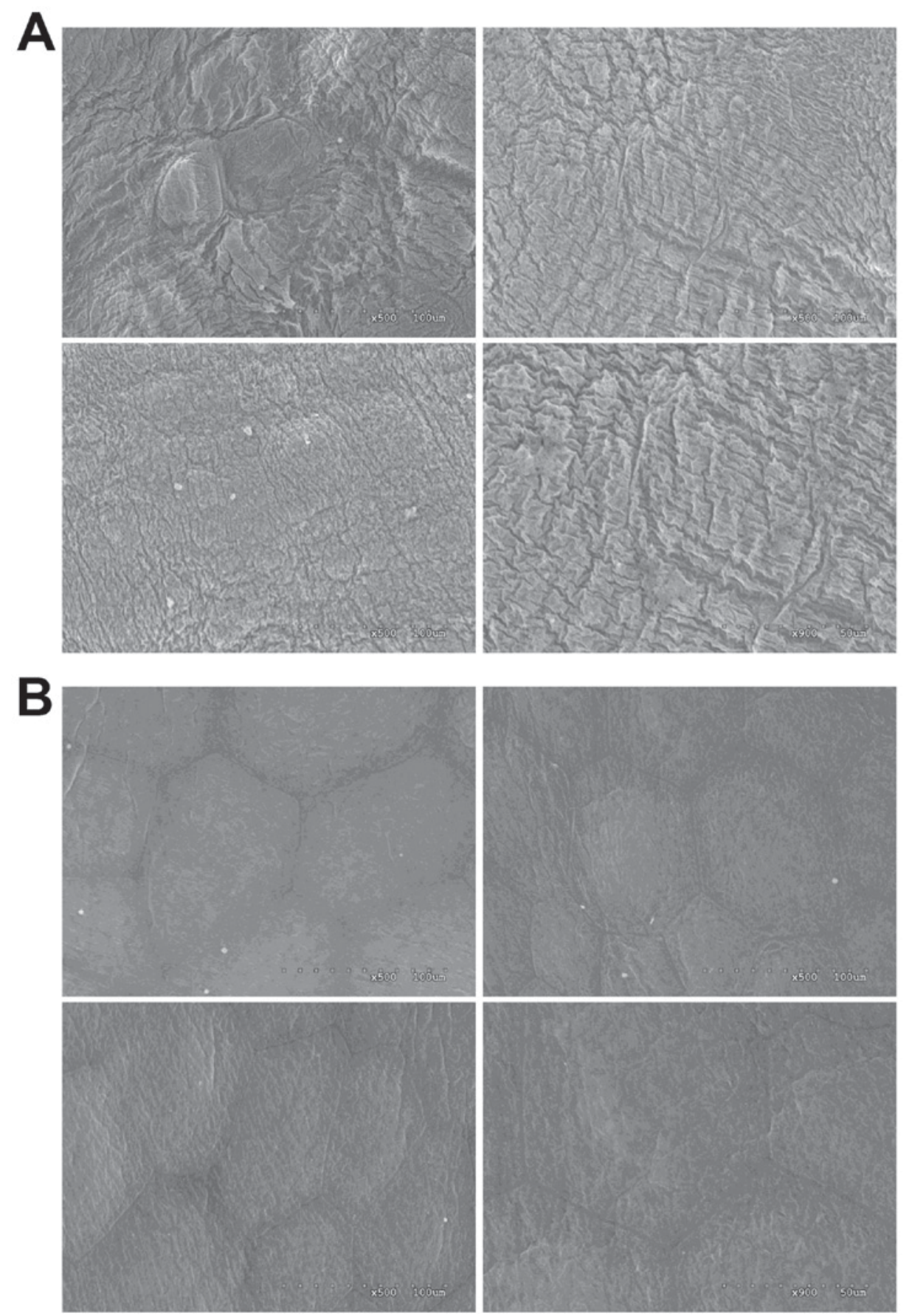

Figure 4. SEM photographs of the mice bladder epithelium. (A) The urothelial plaques of control mice were covered by ridge-shaped structure, indicating preservation of plaques on cytoplasmic membrane (B) The plaque layer on the bladder of ketamine-treated mice was generally much thinner and the tight junction contours of umbrella cells shaped in hexagon are clearly observed. The bladder tissues were photographed under 500x magnification, except for the bottom right one done by $900 x$.

downregulated in mice treated with ketamine, and three genes, VCAN, FN1 and PRKCB, were upregulated in the ketamine group, although the difference was not significant. However, the expression levels of KCNMA1 and RYR1 was not affected, according to the RT-qPCR data. Therefore, the microarray analysis performed represents a strategy to investigate the effects of ketamine on the transcriptome profile.

The role of calcium signaling in ketamine-induced UBSM contraction is presented in Fig. 8. Calcium signaling represents one of the principal causes involved in the abnormal voiding behavior identified in mice treated with ketamine (23). The present results provided the basis for further studies aimed to investigate whether ketamine abuse may cause bladder dysfunction in humans.

\section{Discussion}

Following a 20-week period, the body weights of mice treated with ketamine were significantly lower compared with the control mice, due to a reduced food intake and the side effects of ketamine (21). Additionally, the phenotype observed may be due to physiological stress caused by chronic ketamine 


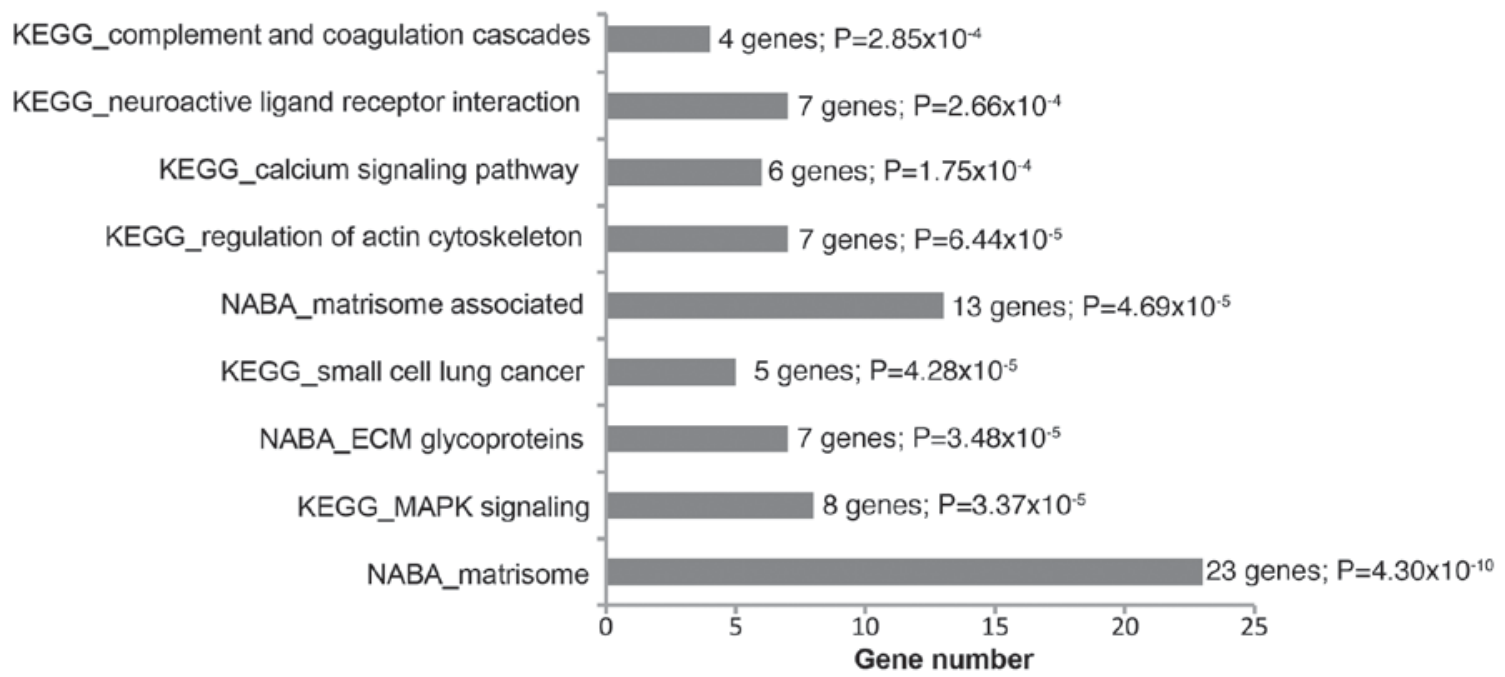

Figure 5. Differentially expressed genes and enriched pathways identified following microarray analysis. Enriched KEGG and NABA pathways are ordered according to their significance. KEGG, Kyoto Encyclopedia of Genes and Genomes; ECM, extracellular matrix; MAPK, mitogen-activated protein kinase.

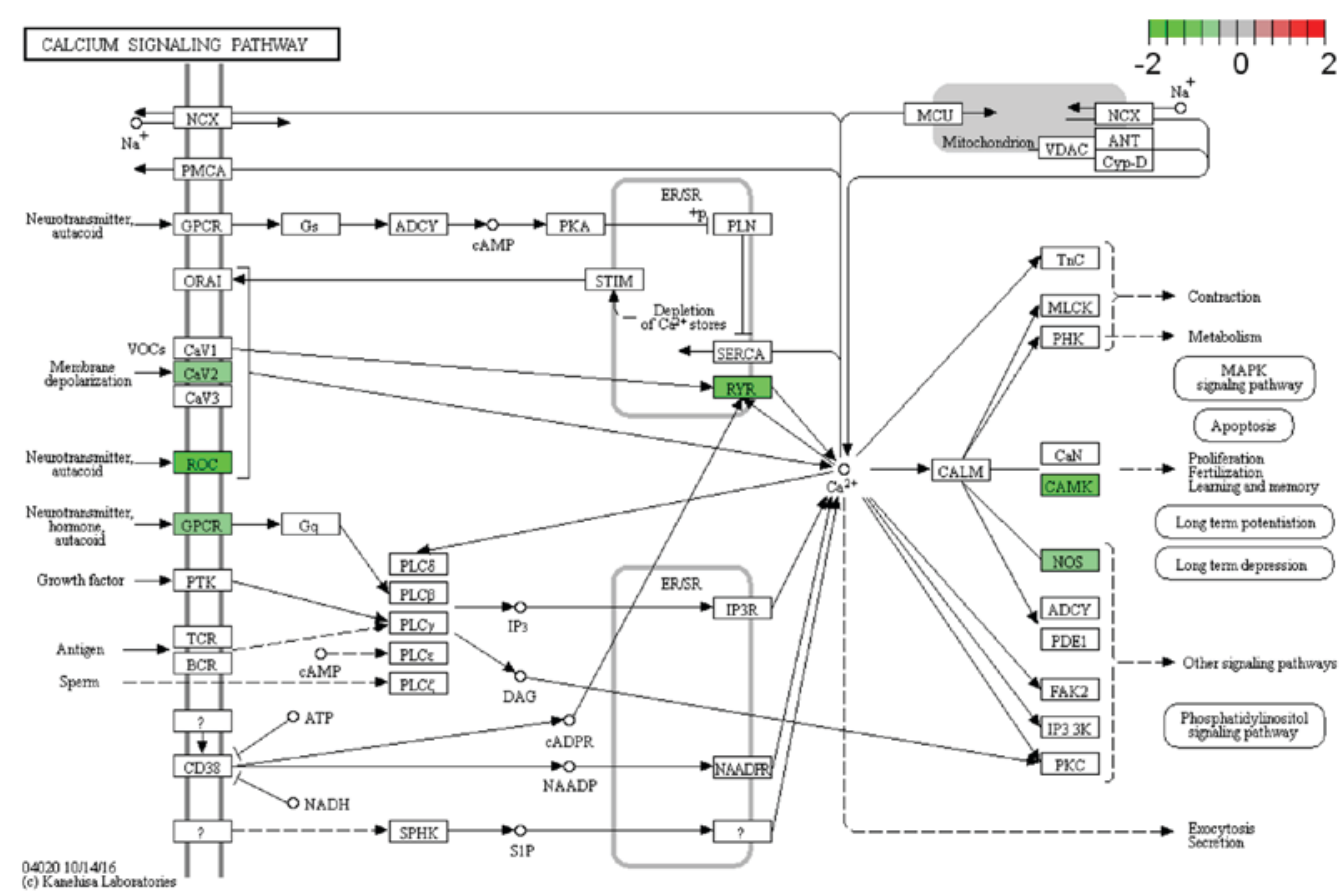

Figure 6. Pathview graph for the Kyoto Encyclopedia of Genes and Genomes term 'calcium signaling pathway' allows the visualization of the differentially expressed genes involved in this signaling pathway. Fold change values in the color bar are expressed in $\log _{2}$ scale. Corresponding gene names: ROC (CHRNA7), GPCR (BDKRB2), CaV2 (CACNA1B), RYR (RYR1), CAMK (CAMK2A), NOS (NOS2).

consumption (26). Nevertheless, mice treated with ketamine exhibited increased micturition frequency and decreased voiding volume compared with the control group, suggesting that long-term treatment with ketamine may lead to urinary bladder overactivity, a symptom previously identified to be associated with patients with $\mathrm{KC} \mathrm{(27).} \mathrm{The} \mathrm{present} \mathrm{finding}$ is consistent with a number of previous studies using rodent models, including mice and rats $(8,10)$. Although the molecular mechanism of ketamine-induced bladder hyperactivity is not fully understood, certain molecular factors, including p-TAGLN (7) and P2RX1 (10), have been proposed to cause detrusor dysfunction.
In the present study, the microarray data suggested that long-term treatment with ketamine may influence detrusor contraction, by influencing the expression of components associated with the calcium signaling pathway. The BK channel is one of the principal potassium channels regulating UBSM function (28). BK channels are expressed in UBSM cells and contain four pore-forming $\alpha$-subunits, KCNMA1, and four regulatory $\beta 1$-subunits, KCNMB1, or $\beta 4$-subunits, KCNMB4 (29). The BK channel has been identified to provide a negative-feedback mechanism to limit the amplitude and duration of UBSM action potentials and associated phasic contractions in response to intracellular $\mathrm{Ca}^{2+}$ spark (30). 

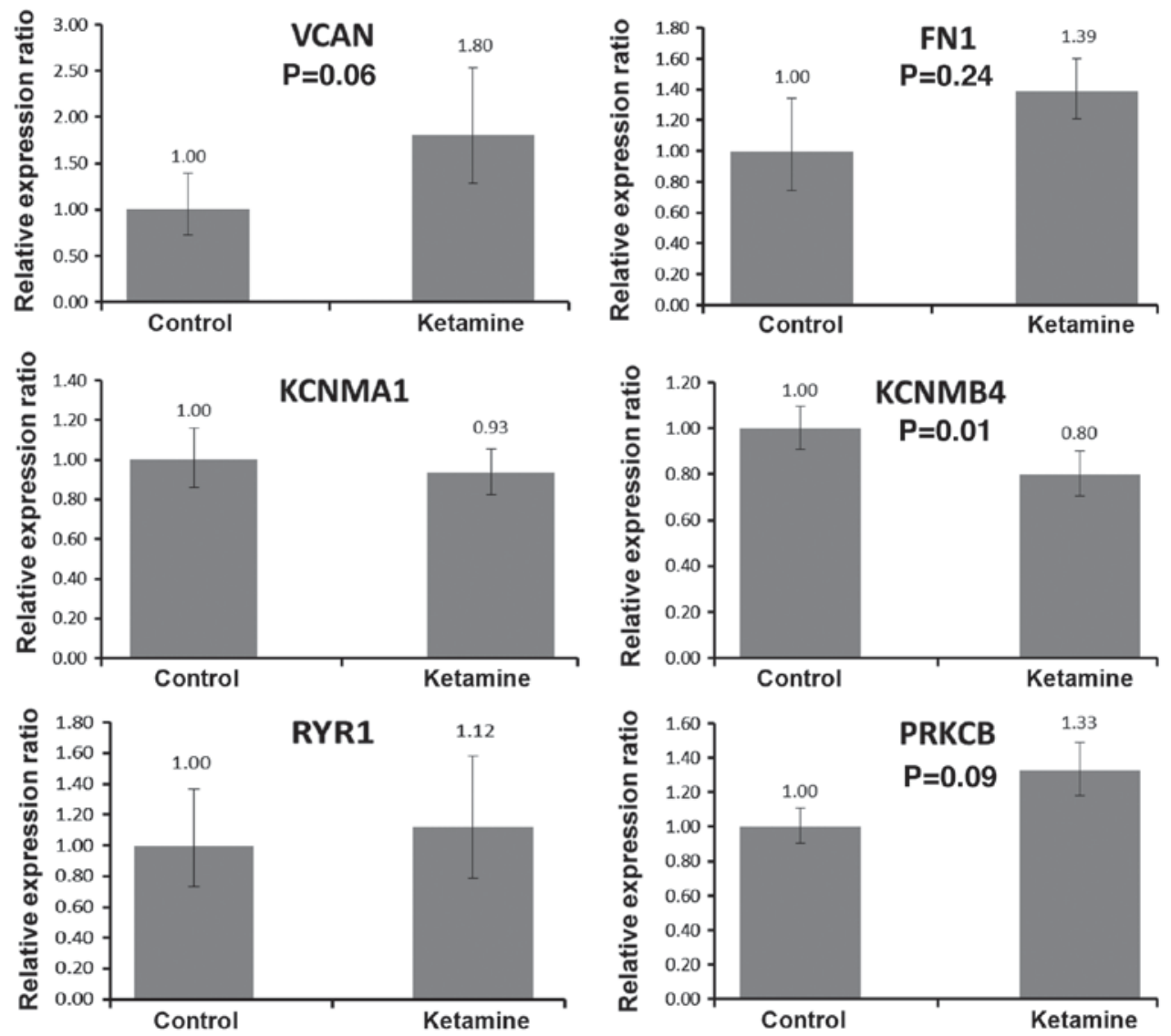

Figure 7. Reverse transcription-quantitative polymerase chain reaction results for six selected genes. The relative expression value of a gene was normalized to the expression of GAPDH. Data are presented as the mean \pm standard deviation. VCAN, versican; FN1, fibronectin 1; KCNMA1, potassium calcium-activated channel subfamily $\mathrm{M} \alpha 1$; KCNMB4, potassium calcium-activated channel subfamily M regulatory $\beta$ subunit 4; RYR1, ryanodine receptor 1; PRKCB, protein kinase C $\beta$.

Decreased gene expression or gene knockout of KCNMB4 was identified to be associated with increased action potential frequency and UBSM excitability $(31,32)$. Therefore, the downregulation of the expression level of KCNMB4, as detected by the present microarray analysis, may represent a cause of the ketamine-associated detrusor overactivity. Furthermore, previous studies suggested that endothelin-1 (EDN1) and its downstream signaling regulated by protein kinase $\mathrm{C}$ (PKC) are able to induce smooth muscle contraction by reducing the frequency of $\mathrm{Ca}^{2+}$ sparks $(33,34)$. PKC is additionally involved in maintaining contractility by inhibiting the myosin light chain (MYL) phosphatase complex activity and subsequently increasing the protein expression level of p-MYL (35). Consequently, the increased expression levels of components of the endothelin pathway, including EDNRB and EDN1, in addition to the increased expression levels of proteins belonging to the $\mathrm{PKC}$ family, including protein kinase $\mathrm{C} \delta$ and PRKCB (36), may promote detrusor contraction, and these genes were identified to be differentially expressed in the present study. Furthermore, the downregulation of the expression level of CAMK2 may represent an additional cause of detrusor contraction, since decreased CAMK2 activity was previously identified to be associated with insufficient local $\mathrm{Ca}^{2+}$ spark and $\mathrm{Ca}^{2+}$ reuptake into the sarcoplasmic reticulum (37). Therefore, the increased cytosolic calcium concentration may promote $\mathrm{Ca}^{2+}$-dependent smooth muscle contraction (38). Collectively, the present study suggested that calcium signaling may serve a role in ketamine-induced bladder hyperactivity.

A VSOP test suggested that ketamine was able to significantly affect the voiding behavior of mice following a 20 -week treatment. Therefore, to avoid additional secondary effects, the treatment was not prolonged beyond the 20th week. The present results suggested that high-dosage long-term ketamine administration promoted inflammatory cell infiltration and vascular congestion in the submucosal layer of the bladder, which were observed in patients with long-term ketamine abuse $(39,40)$. Although the induced inflammatory response was not present in all mice, the pathological outcome was consistent with previous studies using an identical mouse strain, C57BL/6, and a similar ketamine regimen, 100 $\mathrm{mg} / \mathrm{kg} / \mathrm{day}(10,41)$. However, previous studies performed on rat models identified a pronounced and consistent inflammatory response $(7,42)$. This inconsistency in the inflammatory response between rats and mice may be due to the increased metabolic rate of mice (43). Mice may present a decreased retention time of ketamine and its inflammation-associated metabolites, resulting in a decreased induction of inflammation (44). Furthermore, although urothelial thickness was identified to be unaffected in the present study, SEM analysis suggested that the surface of the bladders of mice treated with ketamine was flat and smooth compared with control mice, which exhibited a rough surface with ridge-like structures, suggesting a decreased accumulation of uroplakins in the 


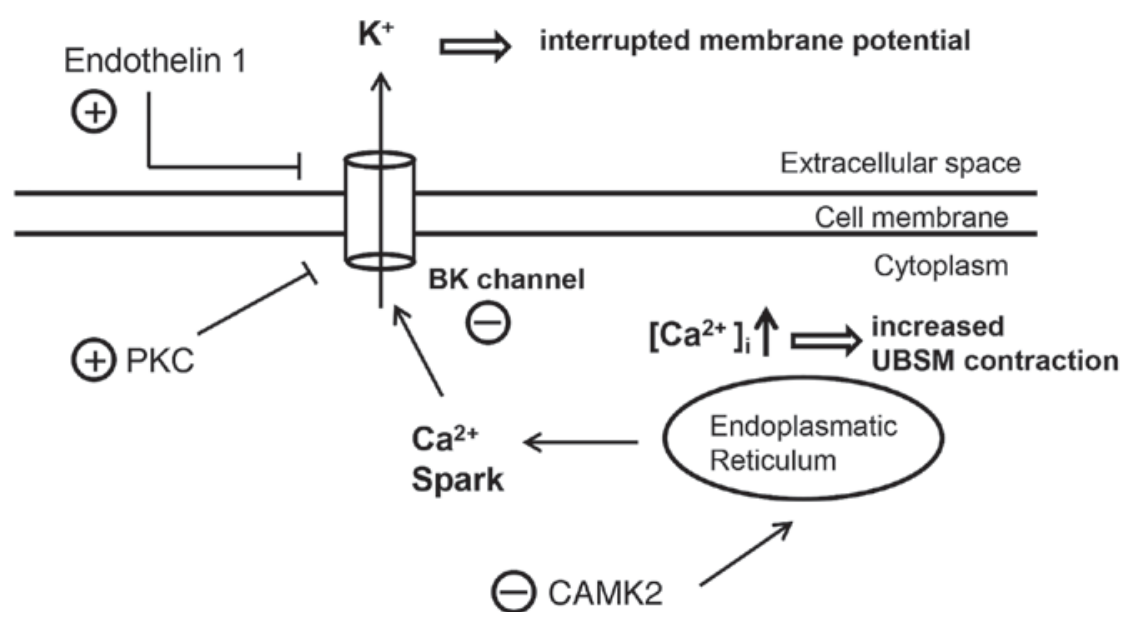

Figure 8. Schematic diagram illustrating the calcium signaling pathway involved in ketamine-mediated dysregulation of UBSM contraction. Genes upregulated following treatment with ketamine are indicated by the symbol +. Downregulated genes are indicated by the symbol -. PKC, protein kinase C; BK, large-conductance voltage- and $\mathrm{Ca}^{2+}$-activated; CAMK2, calcium/calmodulin dependent protein kinase 2; UBSM, urinary bladder smooth muscle.

urothelium. The present microarray data identified a normal expression level of genes encoding for tight junction proteins, including claudin and occludin, suggesting that the function of the urothelium barrier was not affected. The present results are similar to a previous study published by Rajandram et al (44), demonstrating that a low-dosage ketamine regimen $(30 \mathrm{mg} / \mathrm{kg})$, performed for 12 weeks, did not impair the bladder mucosal surface, which exhibited defined tight junctions. However, the present study used a high-dosage, long-term treatment with ketamine $(100 \mathrm{mg} / \mathrm{kg} /$ day for 20 weeks), and it was hypothesized that increased ketamine consumption may affect the morphology of the bladder apical membrane.

Ketamine is able to cause bladder interstitial fibrosis (4), which induces an irreversible decline in bladder function. Our previous study using Balb/c mice suggested that certain molecular events associated with abnormal wound healing processes may contribute to early-stage fibrosis (13). In the present study, using a C57BL/6 mouse model, submucosal extruding folds were observed in the bladders of mice treated with ketamine. Notably, the expression levels of genes involved in ECM deposition, including FN1, LAMC2 and COL1A2, were upregulated, suggesting that long-term treatment with ketamine may promote bladder fibrosis by regulating the ECM. Furthermore, the expression levels of two genes encoding for ECM components associated with fibrosis, VCAN (45) and AGT $(46,47)$, were upregulated. The present results suggested that active fibroblasts, following treatment with ketamine, may secrete these ECM modulators, subsequently inducing fibrogenic response. Previous studies using Sprague Dawley (SD) rats have demonstrated that TGF- $\beta 1$ signaling (48) and EMT (9) are associated with ketamine-induced fibrosis. Furthermore, injection of human umbilical cord blood-derived mesenchymal stem cells or antifibrotic compounds, including $\mathrm{N}$-acetylcysteine (49) and hyaluronic acid (50), in SD rat bladder tissue have been demonstrated to decrease fibrosis by inactivating TGF- $\beta$ signaling. However, TGF- $\beta$-associated genes were unaltered in the present microarray analysis. The inconsistent role of TGF- $\beta$ may be due to development- and species-specific responses. In addition, ketamine-induced fibrosis may be mediated by TGF- $\beta$-independent pathways (42).
Therefore, further investigation is required to elucidate the discrepancies between rats and mice in response to treatment with ketamine.

In the present study, C57BL/6 mice were treated with ketamine for 20 weeks. To examine the effects of long-term ketamine abuse on urinary bladders, the transcriptional profiles were investigated. The calcium signaling pathway was identified as a possible mechanism underlying detrusor contractility and urinary bladder overactivity. The present findings may help in understanding the molecular mechanism underlying $\mathrm{KC}$ and in identifying novel molecular targets for the development of effective therapies to treat ketamine-induced urinary tract syndrome.

\section{Acknowledgements}

Not applicable.

\section{Funding}

The present study was supported by grants from The Ministry of Science and Technology of the Republic of China, Taiwan (grant no. MOST 104-2320-B-415-001-MY3; Taiwan) and from The Ditmanson Medical Foundation Chiayi Christian Hospital Research Program (grant no. R105-008; Taiwan).

\section{Availability of data and materials}

The datasets used and/or analyzed during the present study are available from the corresponding author upon reasonable request.

\section{Authors' contributions}

CHS, STW, and YWL were involved in the design of the study, acquisition and interpretation of data, and drafting the article. STW and SCW performed the experiments. SML and LCL assisted with the SEM experiment. YCD assisted with the histopathological analysis and interpretation. CHS, STW and YWL analyzed and discussed the data. 


\section{Ethics approval and consent to participate}

All animal experiments were approved by The Institutional Animal Care and Use Committee of National Chiayi University (approval no. 104047) and according to the guidelines of The Animal Research: Reporting in vivo Experiments, recommended by The National Centre for the Replacement, Refinement and Reduction of Animals in Research.

\section{Patient consent for publication}

Not applicable.

\section{Competing interests}

The authors declare that they have no competing interests.

\section{References}

1. Domino EF, Chodoff P and Corssen G: Pharmacologic effects of CI-581, a new dissociative anesthetic, in man. Clin Pharmacol Ther 6: 279-291, 1965.

2. Shahani R, Streutker C, Dickson B and Stewart RJ: Ketamine-associated ulcerative cystitis: A new clinical entity. Urology 69: 810-812, 2007.

3. Chu PS, Kwok SC,Lam KM, Chu TY, Chan SW,ManCW, Ma WK Chui KL, Yiu MK, Chan YC, et al: 'Street ketamine'-associated bladder dysfunction: A report of ten cases. Hong Kong Med J 13: 311-313, 2007.

4. Chu PS, Ma WK, Wong SC, Chu RW, Cheng CH, Wong S, Tse JM, Lau FL, Yiu MK and Man CW: The destruction of the lower urinary tract by ketamine abuse: A new syndrome? BJU Int 102: 1616-1622, 2008

5. Jhang JF, Hsu YH and Kuo HC: Possible pathophysiology of ketamine-related cystitis and associated treatment strategies. Int J Urol 22: 816-825, 2015.

6. Chuang SM, Liu KM,Li YL, Jang MY, Lee HH, Wu WJ, Chang WC, Levin RM and Juan YS: Dual involvements of cyclooxygenase and nitric oxide synthase expressions in ketamine-induced ulcerative cystitis in rat bladder. Neurourol Urodyn 32: 1137-1143, 2013.

7. Gu D, Huang J, Yin Y, Shan Z, Zheng S and Wu P: Long-term ketamine abuse induces cystitis in rats by impairing the bladder epithelial barrier. Mol Biol Rep 41: 7313-7322, 2014.

8. Liu KM, Chuang SM, Long CY, Lee YL, Wang CC, Lu MC, Lin RJ, Lu JH, Jang MY, Wu WJ, et al: Ketamine-induced ulcerative cystitis and bladder apoptosis involve oxidative stress mediated by mitochondria and the endoplasmic reticulum. Am J Physiol Renal Physiol 309: F318-F331, 2015.

9. Wang J, Chen Y, Gu D, Zhang G, Chen J, Zhao J and Wu P: Ketamine-induced bladder fibrosis involves epithelial-to-mesenchymal transition mediated by transforming growth factor- $\beta 1$ Am J Physiol Renal Physiol 313: F961-F972, 2017.

10. Meng E, Chang HY, Chang SY, Sun GH, Yu DS and Cha TL: Involvement of purinergic neurotransmission in ketamine induced bladder dysfunction. J Urol 186: 1134-1141, 2011.

11. Gu D, Huang J, Shan Z, Yin Y, Zheng S and Wu P: Effects of long-term ketamine administration on rat bladder protein levels: A proteomic investigation using two-dimensional difference gel electrophoresis system. Int J Urol 20: 1024-1031, 2013.

12. Shen CH, Wang ST, Lee YR, Liu SY, Li YZ, Wu JD, Chen YJ and Liu YW: Biological effect of ketamine in urothelial cell lines and global gene expression analysis in the bladders of ketamine-injected mice. Mol Med Rep 11: 887-895, 2015.

13. Shen CH, Wang SC, Wang ST, Lin SM, Wu JD, Lin CT and Liu YW: Evaluation of urinary bladder fibrogenesis in a mouse model of long-term ketamine injection. Mol Med Rep 14: 1880-1890, 2016.

14. Watanabe H, Numata K, Ito T, Takagi K and Matsukawa A: Innate immune response in Th1- and Th2-dominant mouse strains. Shock 22: 460-466, 2004.

15. Kilkenny C, Browne W, Cuthill IC, Emerson M and Altman DG; National Centre for the Replacement, Refinement and Reduction of Amimals in Research: Animal research: Reporting in vivo experiments-the ARRIVE guidelines. J Cereb Blood Flow Metab 31: 991-993, 2011.
16. Sugino Y, Kanematsu A, Hayashi Y, Haga H, Yoshimura N, Yoshimura K and Ogawa O: Voided stain on paper method for analysis of mouse urination. Neurourol Urodyn 27: 548-552, 2008.

17. Cohen SM, Ohnishi T, Clark NM, He J and Arnold LL: Investigations of rodent urinary bladder carcinogens: Collection, processing, and evaluation of urine and bladders. Toxicol Pathol 35: 337-347, 2007.

18. Livak KJ and Schmittgen TD: Analysis of relative gene expression data using real-time quantitative PCR and the 2(-Delta Delta C(T)) method. Methods 25: 402-408, 2001.

19. Naba A, Clauser KR, Ding H, Whittaker CA, Carr SA and Hynes RO: The extracellular matrix: Tools and insights for the 'omics' era. Matrix Biol 49: 10-24, 2016.

20. Corazza O, Assi S and Schifano F: From 'Special K' to 'Special M': The evolution of the recreational use of ketamine and methoxetamine. CNS Neurosci Ther 19: 454-460, 2013.

21. Cvrcek P: Side effects of ketamine in the long-term treatment of neuropathic pain. Pain Med 9: 253-257, 2008.

22. Lee G: Uroplakins in the lower urinary tract. Int Neurourol J 15: 4-12, 2011.

23. Petkov GV: Central role of the BK channel in urinary bladder smooth muscle physiology and pathophysiology. Am J Physiol Regul Integr Comp Physiol 307: R571-R584, 2014.

24. Wynn TA: Cellular and molecular mechanisms of fibrosis. J Pathol 214: 199-210, 2008.

25. Petkov GV: Role of potassium ion channels in detrusor smooth muscle function and dysfunction. Nat Rev Urol 9: 30-40, 2011.

26. Everds NE, Snyder PW, Bailey KL, Bolon B, Creasy DM, Foley GL, Rosol TJ and Sellers T: Interpreting stress responses during routine toxicity studies: A review of the biology, impact, and assessment. Toxicol Pathol 41: 560-614, 2013.

27. Tsai TH, Cha TL, Lin CM, Tsao CW, Tang SH, Chuang FP, Wu ST, Sun GH, Yu DS and Chang SY: Ketamine-associated bladder dysfunction. Int J Urol 16: 826-829, 2009.

28. Heppner TJ, Bonev AD and Nelson MT: $\mathrm{Ca}(2+)$-activated $\mathrm{K}+$ channels regulate action potential repolarization in urinary bladder smooth muscle. Am J Physiol 273: C110-C117, 1997.

29. Hristov KL, Chen M, Kellett WF, Rovner ES and Petkov GV: Large-conductance voltage- and $\mathrm{Ca} 2+$-activated $\mathrm{K}+$ channels regulate human detrusor smooth muscle function. Am J Physiol Cell Physiol 301: C903-C912, 2011.

30. Hayase M, Hashitani H, Kohri K and Suzuki H: Role of K+ channels in regulating spontaneous activity in detrusor smooth muscle in situ in the mouse bladder. J Urol 181: 2355-2365, 2009.

31. Kita M, Yunoki T, Takimoto K, Miyazato M, Kita K, de Groat WC, Kakizaki H and Yoshimura N: Effects of bladder outlet obstruction on properties of Ca2+-activated $\mathrm{K}+$ channels in rat bladder. Am J Physiol Regul Integr Comp Physiol 298: R1310-R1319, 2010.

32. Brenner R, Chen QH, Vilaythong A, Toney GM, Noebels JL and Aldrich RW: BK channel beta4 subunit reduces dentate gyrus excitability and protects against temporal lobe seizures. Nat Neurosci 8: 1752-1759, 2005.

33. Khimji AK and Rockey DC: Endothelin-biology and disease. Cell Signal 22: 1615-1625, 2010.

34. Jaggar JH, Porter VA, Lederer WJ and Nelson MT: Calcium sparks in smooth muscle.. Am J Physiol Cell Physiol 278: C235-C256, 2000

35. Wang T, Kendig DM, Smolock EM and Moreland RS: Carbachol-induced rabbit bladder smooth muscle contraction: Roles of protein kinase C and Rho kinase. Am J Physiol Renal Physiol 297: F1534-F1542, 2009.

36. Wang T, Kendig DM, Trappanese DM, Smolock EM and Moreland RS: Phorbol 12,13-dibutyrate-induced, protein kinase $\mathrm{C}$-mediated contraction of rabbit bladder smooth muscle. Front Pharmacol 2: 83, 2012.

37. Picht E, DeSantiago J, Huke S, Kaetzel MA, Dedman JR and Bers DM: CaMKII inhibition targeted to the sarcoplasmic reticulum inhibits frequency-dependent acceleration of relaxation and Ca2+ current facilitation. J Mol Cell Cardiol 42: 196-205, 2007.

38. Kuo IY and Ehrlich BE: Signaling in muscle contraction. Cold Spring Harb Perspect Biol 7: a006023, 2015.

39. Lin HC, Lee HS, Chiueh TS, Lin YC, Lin HA, Lin YC, Cha TL and Meng E: Histopathological assessment of inflammation and expression of inflammatory markers in patients with ketamine-induced cystitis. Mol Med Rep 11: 2421-2428, 2015.

40. Jhang JF,Hsu YH,Jiang YH,Lee CLand Kuo HC: Histopathological characteristics of ketamine-associated uropathy and their clinical association. Neurourol Urodyn 37: 1764-1772, 2018. 
41. Duan Q, Wu T, Yi X, Liu L, Yan J and Lu Z: Changes to the bladder epithelial barrier are associated with ketamine-induced cystitis. Exp Ther Med 14: 2757-2762, 2017.

42. Hills CE, Jin T, Siamantouras E, Liu IK, Jefferson KP and Squires PE: 'Special k' and a loss of cell-to-cell adhesion in proximal tubule-derived epithelial cells: modulation of the adherens junction complex by ketamine. PLoS One 8: e71819, 2013.

43. Martignoni M, Groothuis $\mathrm{G}$ and de Kanter R: Comparison of mouse and rat cytochrome P450-mediated metabolism in liver and intestine. Drug Metab Dispos 34: 1047-1054, 2006.

44. Rajandram R, Ong TA, Razack AH, MacIver B, Zeidel M and $\mathrm{Yu}$ W: Intact urothelial barrier function in a mouse model of ketamine-induced voiding dysfunction. Am J Physiol Renal Physiol 310: F885-F894, 2016.

45. Wight TN: Provisional matrix: A role for versican and hyaluronan. Matrix Biol 60-61: 38-56, 2017.

46. Thanigaimani S, Lau DH, Agbaedeng T, Elliott AD, Mahajan R and Sanders P: Molecular mechanisms of atrial fibrosis: Implications for the clinic. Expert Rev Cardiovasc Ther 15: 247-256, 2017.

47. Nogueira A, Pires MJ and Oliveira PA: Pathophysiological mechanisms of renal fibrosis: A review of animal models and therapeutic strategies. In Vivo 31: 1-22, 2017
48. Juan YS, Lee YL, Long CY, Wong JH, Jang MY, Lu JH, Wu WJ, Huang YS, Chang WC and Chuang SM: Translocation of NF- $\kappa \mathrm{B}$ and expression of cyclooxygenase-2 are enhanced by ketamine-induced ulcerative cystitis in rat bladder. Am J Pathol 185: 2269-2285, 2015

49. Kim A, Yu HY, Heo J, Song M, Shin JH, Lim J, Yoon SJ, Kim Y, Lee S, Kim SW, et al: Mesenchymal stem cells protect against the tissue fibrosis of ketamine-induced cystitis in rat bladder. Sci Rep 6: 30881, 2016.

50. Lee YL, Lin KL, Chuang SM, Lee YC, Lu MC, Wu BN, Wu WJ, Yuan SF, Ho WT and Juan YS: Elucidating mechanisms of bladder repair after hyaluronan instillation in ketamine-induced ulcerative cystitis in animal model. Am J Pathol 187: 1945-1959, 2017.

This work is licensed under a Creative Commons Attribution-NonCommercial-NoDerivatives 4.0 International (CC BY-NC-ND 4.0) License. 